\title{
Recovery from severe pulmonary damage due to paraquat administered intravenously and orally
}

\author{
MS HENDY, PS WILLIAMS, P ACKRILL \\ From the Artificial Kidney Unit, Withington Hospital, Manchester
}

The most impressive changes occurring in paraquat toxicity
are to be found in the lung, and when pulmonary lesions
develop radiographically after a latent period death is
almost invariable. There are only two published reports of
patients surviving despite radiographic changes. One
patient developed appearances thought to be due to para-
quat induced pulmonary oedema' ${ }^{1}$ and the other developed
atelectasis and pleural effusions. ${ }^{2}$ We describe a patient
who recovered from diffuse lung damage after self
administration of paraquat by intravenous and oral routes.

\section{Case report}

A 42 year old man had suffered recurrent bouts of endogenous depression for at least 20 years. He was admitted to hospital after intentional intravenous and oral self poisoning using a solution of Weedol (a granular preparation of $2.5 \%$ paraquat with $2.5 \%$ diquat). Two hours before admission he had dissolved the contents of about half a packet of Weedol in $500 \mathrm{ml}$ of cold tap water and injected, using a sterile needle and syringe, two $10 \mathrm{ml}$ aliquots of this solution intravenously. He had then drunk the remainder of the solution. One hour later he dissolved the contents of one full packet of Weedol in about $1000 \mathrm{ml}$ of cold tap water and injected $3 \mathrm{ml}$ of this solution intravenously. He then drank about $500 \mathrm{ml}$ of the remaining solution. He thus took about $2500 \mathrm{mg}$ of both paraquat and diquat, of which about $60 \mathrm{mg}$ of both paraquat and diquat were administered intravenously.

On admission he was not distressed and examination revealed nothing remarkable apart from venepuncture marks in both antecubital fossae. A chest radiograph showed a normal sized heart and clear lung fields.

Initial management consisted of gastric lavage followed by oral administration of Fuller's Earth and magnesium sulphate. A simple qualitative urine test (dithionite) confirmed the presence of paraquat. The four hour blood paraquat concentration was $2 \cdot 3 \mu \mathrm{g} / \mathrm{ml}$. Forced diuresis using ethacrynic acid was started six hours after admission and continued for 18 hours. The 10 hour blood paraquat concentration $0.28 \mu \mathrm{g} / \mathrm{ml}$. On the third day he developed a severe pharyngitis, for which regular Difflam mouth washes $(0.15 \%$ benzydamine hydrochloride) were prescribed. On the fourth day he became dyspnoeic and cen-

Address for reprint requests: Dr MS Hendy, Artificial Kidney Unit, Withington Hospital, West Didsbury, Manchester M20 8LR.

Accepted 13 July 1984 trally cyanosed but had no cough or expectoration of sputum. A chest radiograph showed widespread interstitial and intra-alveolar shadowing compatible with paraquat toxicity (fig). The arterial oxygen tension was $5 \cdot 1 \mathrm{kPa}$ (38 $\mathrm{mm} \mathrm{Hg})$, carbon dioxide tension $3.3 \mathrm{kPa}(25 \mathrm{~mm} \mathrm{Hg})$ and $\mathrm{pH} 7 \cdot 28$. Because of considerable dyspnoea oxygen was reluctantly allowed as required. As a qualitative urine test for paraquat on day 5 was still positive and mild renal failure had developed (serum creatinine concentration $0.23 \mathrm{mmol} / \mathrm{l}(\mathrm{mg} / 100 \mathrm{ml})$ ) two six hour haemoperfusions through an activated charcoal column (Gambro Adsorba 300C) were performed on days 6 and 9. Subsequently no paraquat could be detected in urine or blood. Pathogens were not isolated from repeated blood cultures. The serum creatinine concentration reached a maximum of 0.26 $\mathrm{mmol} / \mathrm{l}(\mathrm{mg} / 100 \mathrm{ml})$ on the seventh day, but mild renal impairment continued for a further 12 days. At no time was the patient oliguric.

Two weeks after admission he no longer required oxygen. The chest radiograph showed right upper lobe collapse with left mid and upper zone confluent shadowing. Both lower zones showed clearing. Results of pulmonary function tests are shown in the table.

Two months later he was well and symptom free.

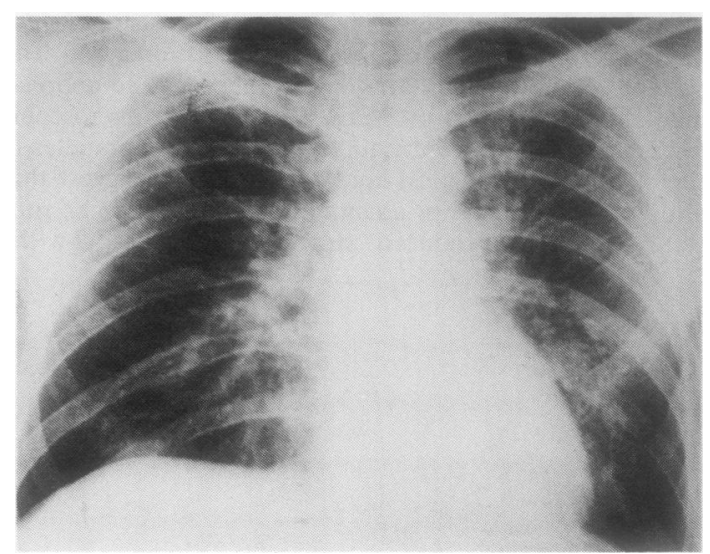

Chest radiograph revealing widespread interstitial and intra-alveolar shadowing on the fourth day of hospital admission. 
Table Results of lung function studies*

\begin{tabular}{|c|c|c|c|c|c|c|c|c|c|}
\hline & \multirow[t]{3}{*}{ Predicted value } & \multicolumn{8}{|c|}{ Days after ingestion } \\
\hline & & \multirow[t]{2}{*}{4} & $\begin{array}{l}6 \\
\text { Before }\end{array}$ & After & $\begin{array}{l}9 \\
\text { Before }\end{array}$ & After & \multirow[t]{2}{*}{14} & \multirow[t]{2}{*}{22} & \multirow[t]{2}{*}{62} \\
\hline & & & \multicolumn{2}{|c|}{ haemoperfusion } & \multicolumn{2}{|c|}{ haemoperfusion } & & & \\
\hline $\begin{array}{l}\mathrm{FEV}_{1}(1) \\
\text { FVC } 1) \\
\text { TLC (1) } \\
\text { TLCO } \\
\mathrm{KCO} \\
\mathrm{PaO}_{2}(\mathbf{k P a}) \\
\mathrm{PaCO}_{2}(\mathbf{k P a}) \\
\text { Arterial pH }\end{array}$ & $\begin{array}{l}4 \cdot 10 \\
5 \cdot 05 \\
6 \cdot 9 \\
10 \cdot 6 \\
1 \cdot 6 \\
11 \cdot 3-12 \cdot 7 \\
4 \cdot 7-6 \cdot 0 \\
7 \cdot 35\end{array}$ & $\begin{array}{l}2 \cdot 86 \\
3 \cdot 36 \\
4 \cdot 3 \\
3 \cdot 5 \\
0 \cdot 8 \\
5 \cdot 1 \\
3 \cdot 3 \\
7 \cdot 28\end{array}$ & $\begin{array}{l}5 \cdot 2 \\
3 \cdot 2 \\
7 \cdot 40\end{array}$ & $\begin{array}{l}2 \cdot 84 \\
3 \cdot 38 \\
4 \cdot 5 \\
3 \cdot 6 \\
0 \cdot 8 \\
7 \cdot 3 \\
3 \cdot 3 \\
7 \cdot 39\end{array}$ & $\begin{array}{l}7 \cdot 4 \\
3 \cdot 8 \\
7 \cdot 40\end{array}$ & $\begin{array}{l}9 \cdot 2 \\
4 \cdot 2 \\
7 \cdot 41\end{array}$ & $\begin{array}{l}3 \cdot 61 \\
4 \cdot 30 \\
5 \cdot 6 \\
5 \cdot 1 \\
0 \cdot 9 \\
9 \cdot 3 \\
5 \cdot 6 \\
7 \cdot 44\end{array}$ & $\begin{array}{c}3 \cdot 71 \\
4 \cdot 60 \\
6 \cdot 3 \\
6 \cdot 3 \\
1 \cdot 1 \\
10 \cdot 1 \\
5 \cdot 6 \\
7 \cdot 41\end{array}$ & $\begin{array}{c}4 \cdot 42 \\
5 \cdot 47 \\
6 \cdot 3 \\
7 \cdot 5 \\
1 \cdot 1 \\
10 \cdot 7 \\
4 \cdot 5 \\
7 \cdot 45\end{array}$ \\
\hline
\end{tabular}

*All arterial samples were taken without supplementary oxygen for at least one hour.

TLC - total lung capacity; TLCO-transfer factor (units $\mathrm{mmol} \mathrm{min}^{-1} \mathrm{kPa}^{-1}$ ); $\mathrm{KCO}-$ transfer coefficient (units mmol min-1 $\left.\mathrm{kPa}^{-1} \mathrm{l}^{-1}\right)$ (Conversion to traditional units $\left.\times 0 \cdot 33\right)$.

\section{Discussion}

This report describes the recovery of a patient with paraquat poisoning severe enough to cause widespread pulmonary damage. There is only one other report of intravenous paraquat administration-the patient succumbed on the twentieth day after poisoning with $2 \mathrm{ml}$ of a commercial preparation of paraquat $(500-600 \mathrm{mg}){ }^{3}$

Although Fuller's Earth may have reduced absorption of the orally administered poison that taken parenterally would have reached the pulmonary circulation in a high bolus concentration. Paraquat is preferentially concentrated in the lung. ${ }^{45}$ Although the total dose of paraquat taken was low the parenteral administration and resulting high serum concentration may have determined the lung damage in our case. Furthermore, the injected granular particles could have contributed to the pulmonary damage, especially as they are likely to have paraquat attached to them, which would ensure a high local concentration.

It is now recognised that paraquat when taken orally may have an early toxic effect on the lung. ${ }^{6}$ Von der Hardt and Cardesa ${ }^{7}$ describe a case of death in two days after Gramoxone ingestion ( $20 \%$ solution of paraquat) in a patient with lung haemorrhage and almost complete loss of alveolar and bronchiolar epithelium was present; and Yoneyama $e t a l^{8}$ found lung haemorrhage in a patient dying one day after swallowing Gramoxone. Our patient, although he did not take a concentrated preparation of paraquat, developed diffuse chest radiographic changes on the fourth day associated with severe respiratory distress. We initially considered his prognosis to be poor as the blood paraquat concentration at four hours was in the lethal range. 9 Oxygen was allowed to alleviate his hypoxic symptoms despite the fact that there is evidence that oxygen increases paraquat lung toxicity. ${ }^{10} \mathrm{He}$ did not have the features of pulmonary oedema described in the case reported by Gardiner,' neither did he develop oliguria or weight gain or have a positive fluid balance during the period of forced diuresis (which had been completed 48 hours before the onset of respiratory symptoms). He thus appears to be unique in surviving widespread pulmonary damage.
The role of haemoperfusion in this case is unclear. The amount of paraquat removed was small (about $0.72 \mathrm{mg}$ ) and we do not think that this affected the outcome despite an improvement in arterial oxygen tension of about $2 \mathrm{kPa}$ (15 mm $\mathrm{Hg}$ ) noted after haemoperfusion.

The case demonstrates that when diffuse interstitial pulmonary damage is found in paraquat poisoning progression is not invariable.

We thank Dr L Smith and the staff at ICI Ltd, Central Toxicology Laboratory, Alderley Park, Cheshire, for performing paraquat measurements and Dr SS Chattergee, Wythenshawe Hospital, Manchester, for performing serial lung function measurements.

\section{References}

1 Gardiner AJS. Pulmonary oedema in paraquat poisoning. Thorax 1972;27:132-5.

2 Fisher HK, Humphries M, Bails R. Paraquat poisoning. Recovery from renal and pulmonary damage. Ann Intern Med 1971;75:407-9.

3 Harley JB, Salomon G, Root RK. Paraquat suicide in a young woman: results of therapy directed against the superoxide radical. Yale J Biol Med 1977;50:481-8.

4 Rose MS, Smith LL, Wyatt I. Evidence for energy-dependent accumulation of paraquat in rat lung. Nature 1974;252:314-5.

5 Raffin TA, Robin ED, Pickersgill J. Paraquat ingestion and pulmonary injury. West $J$ Med 1978; 128:26-34.

6 Proudfoot AT, Stewart MS, Levitt T, Widdop B. Paraquat poisoning: the significance of plasma paraquat concentrations. Lancet 1979;ii:330-3.

7 Fletcher K. Paraquat poisoning. In: Forensic toxicology. Ed. Ballantyne. Publ: J Wright and Sons Ltd. Bristol 1974:86-98.

8 Von der Hardt H, Cardesa A. Early histopathological alterations following paraquat intoxication. Klin Wochenschr 1971;49:544-50:

9 Yoneyama M, Rainuma T, Taravchi I. Swift death by poisoning caused by the new herbicide Gramoxone. Jap J Med Sci Biol 1969;2374:32-4.

10 Flenley DC. Paraquat poisoning. Clinical pathological conference. Scot Med J 1971;16:407-9. 